\title{
Ao rés do chão - Figuras da prosa nas poéticas de Fernando Assis Pacheco e Manuel de Freitas
}

Tamy de Macedo Pimenta

UFF

\section{Resumo}

Este artigo busca pensar as configuraçôes da ideia de prosa no âmbito temático (presença do quotidiano e de elementos banais) e formal (linguagem simples, prosaica e narrativa, com termos e expressóes do dia a dia) na obra poética de Fernando Assis Pacheco (1937-1995) e Manuel de Freitas (1972 - ). Atentando-nos especialmente para como cada um expressa sua relação com a poesia e seu entendimento dela por meio do discurso poético e, no caso de Manuel de Freitas, também do crítico, intenta-se salientar como essas obras, ainda que distantes temporalmente — já que Freitas só começa a publicar nos anos 2000 — compartilham uma noção não-aurática de poesia, por vezes escrevendo, como diria outro poeta, "ao nível das priscas/dos outros"1 e declarando categoricamente para que "Peçam a grandiloquência a outros/ acho-a pulha no estado actual da economia" ${ }^{2}$ ou, ainda, que "Onde se lê poesia deve ler-se nada", ${ }^{3}$ declarando a impotência do próprio gesto de escrita poética.

Palavras-chave: Poesia contemporânea; Prosaísmo; Fernando Assis Pacheco; Manuel de Freitas.

\begin{abstract}
This article intends to reflect on some configurations of the idea of prose in the thematic aspect (presence of daily life and of mundane elements) and in the formal aspect (simple, prosaic and narrative language, full of everyday terms and expressions) in the poetical works of Fernando Assis Pacheco (19371995) and Manuel de Freitas (1972 — ). By paying special attention to how each one of them expresses his relationship with poetry and his understanding of it through poetical discourse and, in the case of Manuel de Freitas, also through the critical one, we intend to emphasize how these works, though temporally distant — since Freitas only started publishing in the 2000's share a non-auratic notion of poetry, sometimes writing, as another poet said, "in the level of the butt/ of others" and declaring categorically that people should "Ask grandiloquence to others/ for I think it despicable in the current state of economy" or, still, "Where one reads poetry we should read nothing", declaring the impotence of the act of poetical writing itself.

Keywords: Contemporary poetry; Prosaism; Fernando Assis Pacheco; Manuel de Freitas.
\end{abstract}

1 CESARINY, Mário. Manual de prestidigitação, 2008, p. 95.

2 PACHECO, Fernando Assis. $A$ musa irregular, 2006, p. 202.

3 FREITAS, Manuel de. Terra Sem Coroa, 2007, p. 38. 
4 BERARDINELLI, Alfonso. Da poesia à prosa, 2007, p.14.

\author{
My work \\ is prose and poetry \\ but I like more Rose \\ than dynasty. \\ My Rose \\ is mine \\ and dynasty \\ I have no one. \\ Poetry only \\ is my dynasty \\ my work \\ but I like prose too \\ when I am with Rose \\ comprennez-vous?
}

António Gancho, $O$ ar da manhã

Meu trabalho/ é prosa e poesia, escreve o português António Gancho no final do século XX, momento em que as fronteiras entre o gênero poético e outras manifestações literárias eram exploradas por artistas e debatidas por pensadores. Se durante esse período muitas foram as tentativas de definir o poético - das quais a "função poética" de Jakobson seria um dos maiores exemplos -, mais recentemente, como afirma Afonso Berardinelli, tal empreendimento foi abandonado pelos estudiosos. Uma vez percebido que "Não há raciocínios, não há provas racionais, não há métodos seguros para aferir a presença da 'qualidade ontológica' chamada poesia em um determinado texto, ${ }^{`}{ }^{\circ}$ o debate acerca da distinção entre poesia e prosa passou a despertar cada vez menos interesse.

Em contrapartida, foi justamente a aproximação entre as duas manifestaçóes literárias e, não raramente, a indissociável fusão entre elas que têm chamado a atenção de teóricos e críticos, sobretudo a partir da publicação dos "Petits poèmes en prose" na França por Baudelaire. Em Ideia da prosa, o filósofo Giorgio Agamben declara ser o enjambement o único aspecto caracterizador do poético, ainda que, por sua própria definição, este seja um elemento que aponta duplamente para a poesia e a prosa:

O enjambement exibe uma não-coincidência e uma desconexão entre o elemento métrico e o elemento sintáctico, entre o ritmo sonoro e o sentido, como se, contrariamente a um preconceito muito generalizado, que vê nela um lugar de encontro, de uma perfeita consonância entre som e sentido, a poesia vivesse, pelo contrário, apenas da sua íntima discórdia. $\mathrm{O}$ verso, no próprio acto com o qual, quebrando um nexo sintáctico, afirma a sua própria identidade, é, no entanto, irresistivelmente atraído para lançar a ponte para o verso seguinte, para atingir aquilo que rejeitou fora de si: esboça uma figura de prosa, mas com um gesto 
que atesta a sua versatilidade [...] $\mathrm{O}$ enjambement traz, assim, à luz o andamento originário, nem poético, nem prosaico, mas, por assim dizer, bustrofédico da poesia, o essencial hibridismo de todo discurso humano. ${ }^{5}$

Nesse sentido, poesia e prosa coexistem simultaneamente dentro da própria estrutura do enjambement, que aponta duplamente para trás (verso) e para diante (prosa) e, por tal motivo, traz o hibridismo essencial de todo discurso humano. Partindo dessa importante reflexão do pensador italiano, desejamos expandir as "figuras da prosa" nomeadas por ele, pensando-as não só como constituintes da própria identidade da versura, mas também como modos de aproximação entre poesia e prosa que, por meio de uma intensificação do prosaísmo nos versos, levam a poesia a um estado de menoridade e pobreza, ao nível da comunicação e do banal cotidiano.

Seguindo essa linha de raciocínio, a prosa passa a ser menos um gênero e mais um ideal, a ser buscado e explorado (ou náo) por poetas a partir da modernidade. Como escreveu o poeta francês Pierre Alféri, a prosa nesse sentido "é o ideal baixo da literatura, melhor dizendo, um horizonte, e lhe sopra um ritmo, uma política." Esse ideal baixo pode ser aproximado das reflexôes de Gilles Deleuze e Félix Guattari sobre literatura menor, entendida como a manifestação de "condiçóes revolucionárias de toda literatura no seio daquela que se chama grande (ou estabelecida)" em que é possível encontrar "seu próprio ponto de subdesenvolvimento, seu próprio dialeto, seu próprio terceiro mundo, seu próprio deserto." Caminhar em direção a prosa dentro da poesia pode, portanto, ser uma forma de escrever essa menoridade, na medida em que inventa novas perspectivas dentro de um sistema pré-estabelecido e, por isso mesmo, constitui-se como um ato político: "A máquina literária toma assim o lugar de uma máquina revolucioná-

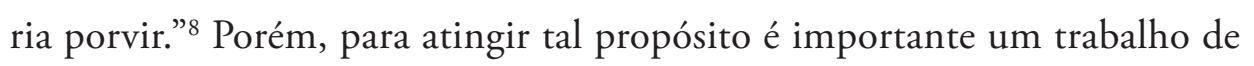
escrita complexo, como ressalta Alféri:

E esse horizonte, essa ideia, por mais livres e amplos que sejam, convocam uma política (portanto, uma crítica) da literatura. Sem prejulgar essa política por vir, falar da literatura enquanto prosa deve permitir - de novo, a partir de agora, enquanto se espera - evocar um trabalho, programas de escrita complexos, precários, sem que por isso se busque apoio em categorias estilísticas; e evocar um modo, mil modos que os livros têm de se afinarem com a "prosa do mundo", sem que por isso se fale de temas (não há temas) [...] Ela jaz nos meandros da sintaxe e na violência dos cortes, esperta, bruta; todos os golpes estão valendo, exceto os que já foram dados. ${ }^{?}$
5 AGAMBEN, Giorgio. Ideia da prosa, 1999, p. 32.

6 ALFÉRI, Pierre. Rumo à prosa. Alea: Estudos Neolatinos, 2013, p. 425.

7 DELEUZE Gilles, GUATTARI, Felix. Kafka: por uma literatura menor, 2014, p. 39.

A fala do poeta, crítico e professor Luis Maffei no I Colóquio Internacional de Poesia Portuguesa Moderna e Contemporânea (UFMG, 2016), intitulada "Este cantar dos anos de pobreza", ao articular a ideia de escassez e menoridade à política, igualmente nos auxiliou a refletir acerca do tema. Nas palavras de Maffei: "a escassez não só cria uma língua menor, mas a expressão poética, ela própria, como minoridade, como resistência que é mais alteração que mera resistência, isto é, uma resistência plástica, tanto no aspecto da mobilidade como da estética. Na literatura como minoridade, o enfrentamento de um lugar-comum poderoso e hegemônico é flagrante, inclusive na mudança da perspectiva sobre os lugares e as coisas, ou melhor, na invenção de novas perspectivas sobre lugares e coisas, na invenção de novos lugares e coisas - sua política, distante dos gabinetes e das práticas majoritárias, pretende-se corrosiva, inclusive, pela sua capacidade de oxidar" MAFFEI, Luis. Este cantar dos anos de pobreza, 2016, s/p.

8 Ibidem, p. 37.

9 ALFÉRI, Pierre. Rumo à prosa. Alea-Estudos Neolatinos, 2013, p. 427. 
10 Ibidem, p. 427.

11 PACHECO, Fernando Assis. $A$ musa irregular, 2006, p. 38.

12 Ibidem, p. 22.
Trata-se, assim, de utilizar certas estratégias a fim de retirar o estatuto aurático da poesia e trazê-la ao rés do chão, aproximando-a do ideal de prosa e menoridade aqui evocados. São essas estratégias, que nomeamos "figuras de prosa" (a partir do texto de Agamben supracitado), as quais procuraremos rastrear brevemente na obra de dois poetas portugueses que respondem ao rumor da prosa com "um humor, não grave, mas baixo como ela". ${ }^{10}$

O primeiro desses poetas começou a publicar nos anos 60, em meio à ditadura salazarista e à guerra colonial portuguesa. Fernando Assis Pacheco esteve inclusive em Angola durante os combates entre 1961 e 1965, experiência em meio a qual escreveu seu primeiro livro, Cuidar dos vivos, publicado em 63. Apesar do cenário da guerra se fazer menos presente neste livro do que em outros posteriores - tal como Câu Kiên: um Resumo, editado pelo próprio autor em 72 e posteriormente publicado sem o disfarce vietnamita como Catalabanza, Quilolo e volta, em 1976 -, o tom simultaneamente irônico e desencantado já pode ser encontrado nesses primeiros poemas, como se pode notar em afirmaçóes céticas acerca do mundo e de si:

\footnotetext{
Não me governam astros. Não me ilude o mistério de qualquer força oculta. Se pouco sei das coisas, de mim mesmo sei o que aprendem os homens solitários, os exploradores solitários da própria cabeça. ${ }^{11}$
}

Essa tendência desencantada, por vezes quase niilista, invade também o fazer poético, seja em zombarias em relação aos poetas que "lamentam-se de mais. / Gastam-se por vezes num choro mais fino, / quase impraticável. Querem ser ouvidos, / e vá de escreverem tal e tal desgraça”, ${ }^{12}$ seja em desconfiança pela própria poesia e o que ela pode diante do mundo, por mais que não falte ao poeta a indignação:

Indignar-me é o meu signo diário.

Abrir janelas. Caminhar sobre espadas.

Parar a meio de uma página,

erguer-me da cadeira, indignar-me

é o meu signo diário.

Há países em que se espera

que o homem deixe crescer as patas

da frente, e coma erva, e leve

uma canga minhota como os bois.

E há os poetas que perdoam. Desliza 
o mundo, sempre estão bem com ele.

Ou não se apercebem: tanta coisa

para olhar em táo pouco tempo,

a vida tâo fugaz, e tanta morte...

Mas a comida esbarra contra os dentes,

digo-vos que um dia acabareis tremendo,

teimar, correr, suar, quebrar os vidros

(indignar-me) é o meu signo diário. ${ }^{13}$
13 Ibidem, p. 25-26.

14 Ibidem, p. 46.

Essa indignação, longe das tendências partidárias neo-realistas tão comuns à época, assemelha-se mais à ideia de testemunho seniana, já que cabe ao poeta não só estar no mundo, mas atentar diariamente para suas injúrias e indignar-se. Se "há os poetas que perdoam... Ou não se apercebem" - o que não é anunciado sem certa ironia corrosiva -, há também a comida a esbarrar contra os dentes, a lembrar-nos constantemente que é preciso "teimar, correr, suar, quebrar os vidros".

Mas o que pode a poesia diante de tamanha indignação? Esse questionamento parece percorrer a obra de Assis Pacheco, que se inscreve simultaneamente na impotência da escrita, questionadora das (im)possibilidades do próprio ato poético, e a dificuldade de realizar esse ato, relacionada a empecilhos de ordem concreta e ontológica (sobretudo ligadas ao cenário da guerra):

O poeta está cercado. Espera-o um avô muito velho.

As cartas chegam com pequenas manchas de lágrimas - alguém ao longe invoca o poeta cercado. E ele grita: afaste-se a noite. Mas vem a noite cercá-lo ainda mais.

Uma casa com um avô muito velho manda revistas, soluços, cartas, apaga-se na distância. (Mas vem o medo cercá-lo ainda mais.)

O poeta escreve os seus papéis furtivamente.

Come com gestos lentos e imprecisos.

Bebe em silêncio. Olha as matas em volta.

Dorme enrolado no seu cobertor

como o romeiro do Senhor da Serra, mas pior, e menos, porque não há deus.

O poeta cintila penosamente

entre o nevoeiro. ${ }^{14}$ 
15 MAGALHĀES, Joaquim Manuel. Dois Crepúsculos: sobre poesia portuguesa actual e outras crónicas, 1985, p. 200- 202.

16 Ibidem, p 54.

17 ALVES, Ida. Quando o poeta vai à guerra: paisagens de morte e ainda amor, 2011, p. 98-99.

18 PACHECO, Fernando Assis. A musa irregular, p. 51.

19 Essa divisão é sugerida por Joaquim Manuel Magalhães em seu texto dedicado a Fernando Assis Pacheco em Dois Crepúsculos: sobre poesia portuguesa actual e outras crónicas, 1981, p. 193-203.
Nessas estrofes, que fecham Cuidar dos vivos e preanunciam a temática de Catalabanza, Quilolo e Volta, a figura do poeta se encontra cercada pelas cenas de guerra e pelas lembranças de casa, intercaladas nos primeiros versos. Em meio a essas condiçóes, cenas banais do cotidiano do poeta-soldado são descritas, porém com especial atenção ao modo como são realizadas: "escreve... / furtivamente / Come com gestos lentos e imprecisos / Bebe em silêncio [...] / Dorme [...] mas pior, e menos, porque não há deus" (grifos meus). A estrofe final condensa a situação do poeta que, em vez de escrever - já que só o consegue secretamente - luta penosamente para sobreviver entre o nevoeiro de tiros, angústias e medos. De fato, como aponta o crítico e também poeta português Joaquim Manuel Magalhães em comentário sobre Catalabanza, Quilolo e Volta, mas que também se aplica, em nosso entendimento, a todos os poemas sobre o testemunho da guerra escritos por Assis Pacheco:

\begin{abstract}
Ele é sinal do corte insuportável da pessoa para uma inglória tarefa, a perspectiva do homem transferido para os infernos da separação, a sujeição ao horror de uma guerra que se não quer fazer [...] O ímpeto deste livro é ter reconhecido a miséria dessa situação humana. A sua vitória é ter ousado contar o homem sujeito à violação de ter que lutar pelo que não queria. Fala-nos da ausência radical de heroísmo pela voz de um anti-herói que é heroico pela consciência com que diz a verdade radical de si e de uma situação colectiva. ${ }^{15}$
\end{abstract}

Se então, por um lado, é difícil para o poeta escrever em meio ao conflito - de onde às vezes consegue "salvar um verso / escrito no primeiro dia"16 -, por outro, é igualmente (ou até mais) penosa a tarefa da escrita de poesia conseguir dar conta de tal testemunho. Contudo, é justamente desta aporia que os poemas de guerra deste português se fazem, promovendo uma consciência política que não se deixa ser panfletária, ao abandonar demagogias e sentimentalismos em favor de um "olhar sobre a paisagem da guerra [que] pousa sobre as coisas e os gestos triviais do dia a dia, constatando morte e dor como faces de uma realidade que o sujeito lírico atravessa com certa ironia a controlar a emoção," 17 ainda que a dor resista arduamente: "Dizem que a guerra passa: esta minha / passou-me para os ossos e não sai”. ${ }^{18}$

Essa atenção a pormenores banais do dia-a-dia é uma marca da poética de Fernando Assis Pacheco, seja no grupo de poemas voltado para a temática pessoal civil, seja no outro marcado pela experiência da guerra ou, ainda, nos poemas que envolvem os dois eixos. ${ }^{19}$ Juntamente com um uso irrestrito da problemática pessoal (envolvendo não raramente dados biográficos assumidos), que não teme o tom "confessional" rejeitado por vários poetas de 
sua geração pós-Presença, e de um vocabulário comum, corriqueiro e por vezes chulo, essa exploração de cenas cotidianas é uma das mais fortes figuras de prosa empregadas por este poeta. A poesia, em vez de ser um espaço para temas e vocábulos "altos", se torna lugar de preocupaçôes pessoais, recordaçôes amorosas e observações triviais e, mesmo quando trata da guerra, é por um olhar desviante que nota "como se bebia /água podre. / Não falando no vinho, muito. / Durante os ataques doía-me um joelho". ${ }^{20}$

Além dessas figuras, há a presença por vezes discreta, mas recorrente, de uma desconfiança em relaçáo à poesia. O poeta troça de grandes ambiçóes almejadas por outros escritores, aproximando a poesia dos fazeres comuns e até mesmo renunciando a ela por pequenos prazeres,

faço versos para retardar o acidente coronário podia fazer ginástica de manutenção que era o mesmo

disse de vez: ao diabo o nome nos índices remissivos!

escrevam teses sobre a prenhez do referente

deixem-me olhar a chuva deixem-me

palitar os dentes - ut supra ${ }^{21}$

ou por tarefas mais úteis:
20 Ibidem, p. 63.

21 Ibidem, p. 154.

22 Ibidem, p. 207.

23 Ibidem, p. 175.

24 Ibidem, p. 202. as artes nobres: varrer sachar empar
e outras: bordar coser fazer renda
não tenho nada contra a poesia
mas é mais útil a limpeza a seco ${ }^{22}$

À essa desconfiança em relação à poesia, soma-se o já citado desprezo por um tom grandioso e alto empregado em certa poesia e a consequente asserção de um tom menor, como em "cantei tão pouco e só em tom menor", 23 "Peçam a grandiloquência a outros / acho-a pulha no estado actual da economia", ${ }^{24}$ ou ainda na clara mensagem do "Soneto contra as pesporrências" para leitor:

\footnotetext{
É favor não pedirem a esta poesia que faça o jeito às alegadas tendências do tempo nem às vãs experiências que sempre a deixaram de mão fria o que iria bem mas mesmo bem seria num jornal a coluna das ocorrências as coisas da vida mais que as pesporrências editoriais do comentador do dia
} 
25 Ibidem, p. 162.

26 FREITAS, Manuel de. Incipit, 2015, p. 9.

27 Ibidem, p. 51.

28 Idem, Cretcheu Futebol Clube, 2006, p. 25.

29 Idem, Poetas sem qualidades, 2002, p. 9.

30 Não é nosso intuito aqui se alongar na discussão acerca da antologia. Todavia, é interessante deixar para o leitor algumas das características que, segundo Manuel de Freitas, unem os poetas sem qualidades ali reunidos: "O que, de alguma maneira, aproxima estes nomes (e legitimará, porventura, reuni-los num mesmo livro) são, precisamente, as várias "qualidades" que notoriamente não possuem. Estes poetas não são muita coisa. Não são, por exemplo, ourives de bairro, artesãos tardo-mallarmeanos, culturalizadores do poema digestivo, parafraseadores de luxo, limadores das arestas que a vida deveras tem. Podemos, pelo contrário, encontrar em todos eles um sentido agónico (discretíssimo, por vezes) e sinais evidentes de perplexidade, inquietação ou escárnio perante o tempo e o mundo em que escrevem. Não serão, de facto, poetas muito retóricos (embora à retórica, de todo, se não possa fugir), mas manifestam força - ou admirável fraqueza - onde outros apenas conseguem ter forma ou uma estrutura anémica. Comunicam, em suma; não pretendem agradar ou ser poeticamente correctos. Só é possível falar destes poetas negativamente (e ainda bem): aproxima-os a falta de todas essas qualidades em que os meus contemporâneos se têm revelado pródigos. Por isso estão aqui, a desabrigo, a dizer o que dizem”. FREITAS, Manuel de. Poetas sem qualidades, 2002, p. 1415 , grifos do autor. o que vai mal com ela são as petulâncias de que se vestem muitas redundâncias dando-se públicos ares de sabedoria

que o leitor farto das arrogâncias magistrais troca por outras instâncias onde pode mandá-las pra casa da tia ${ }^{25}$

O tom simultaneamente irônico, corrosivo e provocador dos versos de Fernando Assis Pacheco parecem ecoar em "Tempo dos puetas", prefácio da polêmica antologia Poetas sem qualidades, organizada pelo editor, poeta e crítico Manuel de Freitas no início do século XXI. Decerto, não é surpreendente que encontremos referências e dedicatórias a Assis Pacheco na obra poética de Freitas, além de um texto sobre Cuidar dos vivos em Incipit, obra que reúne comentários acerca de "algumas das mais vigorosas estreias poéticas ocorridas em Portugal durante o século XX", ${ }^{26}$ no qual, dentre outros elogios, Freitas afirma que:

\begin{abstract}
Assis Pacheco esteve, de certo modo, muito à frente de seu tempo. Refiro-me à desconfiança para com um lirismo manso, jovialmente reprodutor de inócuas e exauridas estagnaçôes; mas uma desconfiança que vai ao ponto de sabotar ou pôr em causa a própria poesia [...] Fernando Assis Pacheco olha de esguelha a poesia, esventrando ou ridicularizando as habituais facilidades líricas. $^{27}$
\end{abstract}

Assim, ainda segundo Freitas, a "sensação de uma língua e linguagem gastas" encontradas nos versos de Assis Pacheco pode auxiliar na compreensão do "rumo inquieto de alguma poesia portuguesa mais recente". Enquanto o poeta-soldado olhou a poesia de esguelha aos fins do século XX, Manuel de Freitas, já em nosso século, parece mirá-la de frente e declarar sua inutilidade e impotência: "Os poemas, / esses, pouco ou nada valem" ${ }^{28}$

Se "A um tempo sem qualidades, como aquele em que vivemos, seria no mínimo legítimo exigir poetas sem qualidades", ${ }^{29}$ como seriam, então, os poemas oriundos desse tempo que respondem a essa falta de qualidades? Sem pretensão de caracterizar integralmente tal forma de poesia - a que o próprio Freitas tenta, se não definir, ao menos esboçar linhas gerais no prefácio à antologia ${ }^{30}$, interessa-nos exemplificar por meio de alguns versos como esse "sem qualidades" se aproxima de uma ideia de prosa, de menoridade, semelhante à perseguida por Fernando Assis Pacheco. Dedicado a este 

empregadas por Freitas em seu trabalho poético:

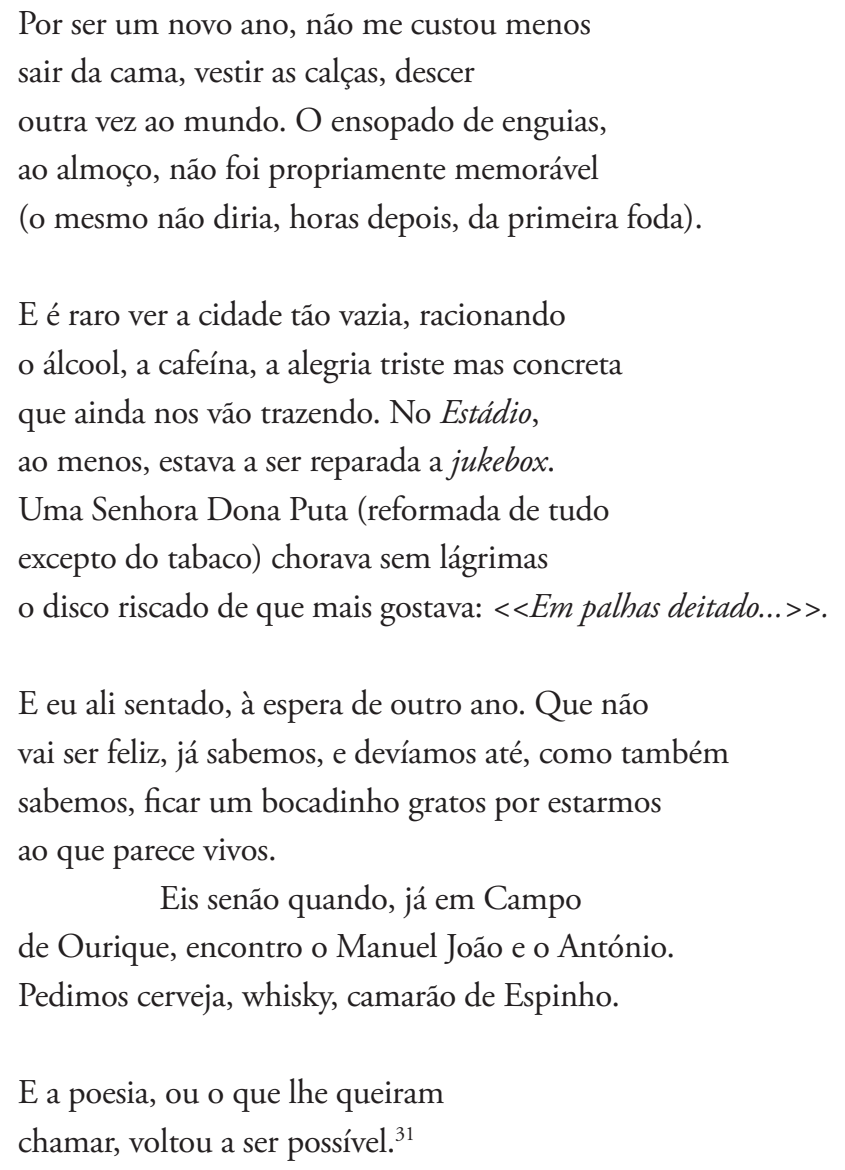

O novo ano referido não está, decerto, inserido em um contexto de guerra como em tantos poemas de Assis Pacheco: reporta-se a um outro tempo, muito embora a percepção do tempo não seja tão outra, tão diferenciada, da escrita do autor de Catalabanza, Quilolo e volta. Ainda que reconheça ironicamente que deveria estar "um bocadinho grato" por estar aparentemente vivo, o sujeito lírico vivencia somente uma "alegria triste mas concreta" enquanto observa, semelhantemente ao poeta a que dedica esses versos, pormenores que acontecem em volta de si, numa taberna ao fim / início de mais um ano que, entretanto, não causa nenhuma mudança à paisagem ou a própria vida: "E eu ali sentado, à espera de outro ano. Que não / vai ser feliz, já sabemos”.

Esse cenário de desencanto, marcado por observações quotidianas e vocabulário e construção sintática simples - tal qual Assis Pacheco -, só será amenizado (embora não totalmente) pelo encontro do sujeito com "o Manuel João e o António". Diante de um contexto amargo e violento (de uma outra violência, diversa da de guerra), é a presença de amigos, de afeto, que permite que "a poesia, ou o que lhe queiram / chamar" volte a ser possível. E aqui, mais uma vez, Assis Pacheco e Freitas se aproximam, pois 
32 ALVES, Ida. Quando o poeta vai à guerra: paisagens de morte $\mathrm{e}$ ainda amor, 2011, p. 101.

33 FREITAS, Manuel de. Jukebox 3, 2012, p. 28.

34 Idem, [Sic], 2002, p. 20.

35 Idem, Poetas sem qualidades, 2002, p. 14.

36 Idem, Estádio, 2008, p. 11.

37 Tais como o poeta, crítico e professor Marcos Siscar, em seu ensaio "Figuras de prosa: a ideia da 'prosa' como questáo de poesia" no livro $O$ duplo estado da poesia: modernidade e contemporaneidade, 2015, p. 29-40. como observou Ida Alves, o primeiro "não cessa de entrecruzar a morte com $\mathrm{o}$ amor, a violência com o afeto, e essa contraposição tem um valor bastante especial no contexto de sua obra. A memória do amor é o contraveneno para a realidade à volta e é dita com as mesmas imagens do horror", ${ }^{32}$ enquanto o segundo, como vimos, somente concebe a poesia na presença de amigos:
Eercado de amigos, é uma violência necessária.
cera quer poemas, mesmo

Não me refiro ao timbre ou à dicção, talentos que sempre desconheci. Posso apenas dizer-vos: esta é a minha dor, a única coisa que me prende ao mundo. ${ }^{33}$

Esse sujeito poético está cercado não por guerrilhas, mas por amigos, porém, assim como Assis Pacheco, vê no ato da escritura e leitura de poesia uma "violência necessária" que tem de ser realizada ainda que furtivamente, em meio ao caos, como bem soube o primeiro. Ambos não possuem, e podemos dizer que não almejaram possuir, os talentos da dicção e da grandiloquência - "É por esses e outros motivos / que não gosto assim tanto / dos poetas meus contemporâneos", ${ }^{34}$ diz Freitas - e, ao não se iludirem quanto aos poderes da poesia, ridicularizam a ela e a seus seguidores "parafraseadores de luxo, limadores das arestas": 35

\author{
Porque a poesia, meu amigo, \\ apesar de todas as opinióes contrárias, \\ continua a ser uma tara higiénica \\ que nunca nos libertará da morte: \\ rudefrauta, malsofrida e desalegre. ${ }^{36}$
}

Ao se recusarem a utilizar um grande trabalho retórico - ainda que dela, de todo, não se possa fugir, como nos lembra Freitas - esses dois poetas optaram, como intentamos demonstrar, por estratégias que podemos aproximar da ideia de prosa discutida por Agamben, Alféri, dentre outros ${ }^{37}$ e as quais chamamos "figuras de prosa", apropriando-nos e expandindo o termo empregado pelo filósofo italiano. Dentro desse contexto de desauratização do gênero poético, resta a nós - e aos poetas, em seus devidos tempos de escritura - a questão: por que continuar a escrever poesia? A qual, parecem responder, ainda que precariamente, os afetos, 


\author{
Quando os anos passarem \\ sobre esse teu desgosto \\ vais ver que te curaste \\ não de vez mas um pouco \\ pois o que a gente busca \\ nas dobras do amor \\ é a cura para a morte \\ que não tem consolo ${ }^{38}$
}

afinal, se "Onde se lê poesia deve ler-se nadal [...] Onde se lê amizade deve ler-se amizade." ${ }^{39}$, ainda. ${ }^{40}$

\section{Referências}

AGAMBEN, Giorgio. Ideia da prosa. Trad. João Barrento. Lisboa: Cotovia, 1999.

ALFÉRI, Pierre. Rumo à prosa. Trad. Masé Lemos e Paula Glenadel. Alea - Estudos Neolatinos. v. 15, n. 2, jul. / dez. 2013. Disponível em: http://www.scielo.br/pdf/ alea/v15n2/11.pdf. Acesso em: 27 julho 2018.

ALVES, Ida. Quando o poeta vai à guerra: paisagens de morte e ainda amor. In: CAVALCANTI PADILHA, Laura; SILVA, Renata Flavia da. De guerras e violências: palavra, corpo, imagem. Niterói: Editora da UFF, 2011, p. 95-103.

BERARDINELLI, Alfonso. Da poesia à prosa. Trad. Maria Betania Amoroso. Rio de Janeiro: Cosac Naify, 2007.

CESARINY, Mário. Manual de prestidigitação. Lisboa: Assírio \& Alvim, 2008.

DELEUZE, Gilles; GUATTARI, Félix. Kafka: por uma literatura menor. Trad. Cíntia Vieira da Silva. Belo Horizonte: Autêntica editora, 2014.

FREITAS, Manuel de. O tempo dos puetas. In: Poetas sem Qualidades. Lisboa: Averno, 2002.

FREITAS, Manuel de. [Sic]. Lisboa: Assírio \& Alvim, 2002.

FREITAS, Manuel de. Cretcheu Futebol Clube. Lisboa: Assírio \& Alvim, 2006.
38 PACHECO, Fernando Assis. Respiração Assistida, 2003, p. 23.

39 Idem, Terra Sem Coroa, 2007, p. 38.

40 Onde se lê Deus deve ler-se morte. Onde se lê poesia deve ler-se nada. Onde se lê literatura deve ler-se $o$ quê? Onde se lê $e u$ deve ler-se morte. Onde se lê amor deve ler-se Inês. Onde se lê gato deve ler-se Barnabé. Onde se lê amizade deve ler-se amizade. Onde se lê taberna deve ler-se salvação. Onde se lê taberna deve ler-se perdição. Onde se lê mundo deve ler-se tirem-me daqui. Onde se lê Manuel de Freitas deve ser com certeza um sítio muito triste. (FREITAS, Manuel de. Terra sem coroa, 2007, p. 38). 
FREITAS, Manuel de. Incipit. Lisboa: Averno, 2015.

GANCHO, António. O ar da manhã. Lisboa: Assírio \& Alvim, 1995.

MAFFEI, Luis. Este cantar dos anos de pobreza. In: I Colóquio Internacional de Poesia Portuguesa Moderna e Contemporânea, UFMG, 2016.

MAGALHÃES, Joaquim Manuel. Dois Crepúsculos: sobre poesia portuguesa actual e outras crónicas. Lisboa: A Regra do Jogo, 1981.

PACHECO, Fernando Assis. A musa irregular. Lisboa: Assírio \& Alvim, 2006.

PACHECO, Fernando Assis. Respiração Assistida. Lisboa: Assírio \& Alvim, 2003.

SISCAR, Marcos. Figuras de prosa: a ideia da "prosa" como questâo de poesia. In: SCRAMIM, Susana; SISCAR, Marcos; PUCHEU, Alberto (Orgs). O duplo estado da poesia: modernidade e contemporaneidade. São Paulo: Iluminuras, 2015, p. 29-40.

Submissão: 09/08/2018

Aceite: $11 / 11 / 2018$

https://doi.org/10.5007/2176-8552.2018n25p45 